\title{
Growth and Characterisation of a New Semi-Organic Nonlinear Optical TTMZS Single Crystal
}

\author{
Bhuvaneswari Arvind \\ KCG College of Technology, \\ Karapakkam, Chennai 600097 \\ India.
}

\author{
R.Dhanasekaran \\ Crystal Growth Centre, Anna University \\ Guindy, Chennai 600025 \\ India.
}

\begin{abstract}
A new semi-organic nonlinear optical crystal called Tris Thiourea Magnesium Zinc sulphate (TTMZS) was synthesized. TTMZS single crystals were grown from an aqueous solution using the Slow Evaporation method. The solubility of TTMZS was determined for various temperatures. Single Crystal X-ray Diffraction (XRD) study was carried-out to identify the lattice parameters. Various diffracting planes of the grown crystal were identified from the powder XRD study. Fourier Transform Infrared (FT-IR) studies confirm the various functional groups present in the grown crystal. The transmission spectrum of this crystal shows that the lower cut off wavelength lies at $280 \mathrm{~nm}$. The thermal analysis confirmed that the crystal is stable up to $248.46^{\circ} \mathrm{C}$. The Nonlinear Optical (NLO) property of the grown crystal has been confirmed by Kurtz powder Second Harmonic Generation (SHG) test.
\end{abstract}

Keywords: Crystal growth; Crystal Structure; X-ray Diffraction; Semi-Organic Material; Nonlinear Material

\section{INTRODUCTION}

Nonlinear Optical (NLO) crystals have great technological significance in the fields of Opto Electronics, Digital Signal Processing, Instrumentation and Optical Communication $[1,2]$. In the recent years semi-organic NLO crystals are attracting a great deal of attention due to their high NLO efficiency, low damage threshold and high mechanical strength as compared to their organic NLO counterparts. In semi-organic materials the organic ligand is attached to the inorganic host by an ionic bond. Therefore semi-organic crystals have higher chemical stability and mechanical strength compared to their inorganic counterparts [3]. Among semi-organic NLO materials, the metal complexes of thiourea have a low UV cut-off wavelength. This feature of Thiourea finds significant application in the fields of High Frequency Conversion and Second Harmonic Generation [4-8]. Thiourea being a naturally centro-symmetric molecule doesn't exhibit NLO properties; however when it forms complexes with metal ions, it NLO characteristics. Zinc Thiourea Sulphate (ZTS) is an already-reported NLO material for type II Second Harmonic Generation. It is nearly 1.2 times more nonlinear than KDP [9]. Some of the efficient NLO crystals of metal organic complexes of thiourea such as Zinc Thiourea Chloride (ZTC) [10], Bis Thiourea Cadmium Chloride (BTCC) [11] and Tris Thiourea Magnesium Sulphate (MTS) [12] have already been reported. In this communication, a new metalorganic NLO crystal of Tris Thiourea Magnesium Zinc Sulphate TTMZS is reported for the first time and the grown crystals have been characterized by various techniques.

\section{EXPERIMENTAL PROCEDURES}

\subsection{Crystal Synthesis}

TTMZS salt was synthesized by dissolving Thiourea (AR grade), Magnesium Sulphate Hepta Hydrate (AR grade) and Zinc Sulphate Hepta Hydrate (AR grade) in the ratio www.ijsea.com
3:0.25:0.75 in double distilled water. The prepared solution was slightly heated and the solvent allowed to evaporate. TTMZS was synthesized as per the following reaction:

$3\left[\mathrm{CS}\left(\mathrm{NH}_{2}\right)_{2}\right]+\mathrm{MgSO}_{4} \cdot 7 \mathrm{H}_{2} \mathrm{O}+\mathrm{ZnSo}_{4} \rightarrow \mathrm{MgZn}\left[\mathrm{CS}\left(\mathrm{NH}_{2}\right)_{2}\right]_{3} \mathrm{SO}_{4} \cdot 7 \mathrm{H}_{2} \mathrm{O}$

The synthesized TTMZS salt was purified by successive recrystallization process.

\subsection{Crystal Growth}

In order to grow bulk single crystals of TTMZS, the solubility of the synthesized material was determined at different temperatures $\left(35-45^{\circ} \mathrm{C}\right)$. The gravimetric method was adopted to determine solubility and this was carried out in a constant temperature bath $\left( \pm 0.01^{\circ} \mathrm{C}\right)$. The solution was stirred continuously for 6 hours using a magnetic stirrer. The saturated solution prepared at $35^{\circ} \mathrm{C}$ was filtered using Whatman filter paper. The filtered solution was taken in a beaker and closed with a perforated cover. It was kept in a constant temperature bath maintained at $35^{\circ} \mathrm{C}$. The solvent was allowed to evaporate slowly. TTMZS crystals of

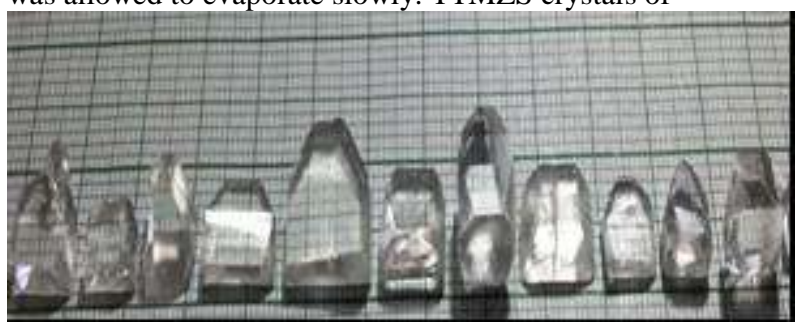

Figure 1. TTZMS crystals grown using Solvent Evaporation method.

optimum size were harvested from the mother solution in a time span of 30 days. The TTMZS crystals thus grown are shown below. 


\section{RESULTS AND DISCUSSION:}

\subsection{X-Ray Diffraction Analysis}

The grown crystals were subjected to Single Crystal X- ray Diffraction using an ENRAF NONIUS CAD-4 diffractometer with $\operatorname{Mo~} \mathrm{K} \alpha(\lambda=0.71073 \AA)$ radiation at room temperature. The crystal belongs to orthorhombic system. The observed unit cell parameters are given in Table 1 below and the observed values are compared with the reported values of Tris Thiourea Magnesium Sulphate.

Table 1. Indexed Powder XRD Pattern of TTMZS.

\begin{tabular}{|c|c|c|c|c|c|}
\hline \multirow[t]{2}{*}{ SI.No } & \multicolumn{3}{|c|}{$\begin{array}{l}\text { Cell Parameters in } \\
\text { Angstrom Units }\end{array}$} & \multirow[t]{2}{*}{$\begin{array}{c}\text { Volume } \\
{ }^{3} \\
\text { in } \AA\end{array}$} & \multirow[t]{2}{*}{$\begin{array}{c}\text { System } \\
\alpha=\beta=\gamma=90\end{array}$} \\
\hline & a & b & c & & \\
\hline TTMZS & 15.572 & 6.315 & 5.549 & 545.46 & Orthorhombic \\
\hline$T M S$ & 5.482 & 7.672 & 8.562 & 360 & Orthorhombic \\
\hline
\end{tabular}

The Powder XRD pattern of TTMZS was recorded using a Rich Seifert diffractometer with $\mathrm{Cu} \mathrm{K} \alpha \quad(\lambda=1.54059 \AA)$ radiation. The powder sample was scanned over the range of $10-80^{\circ}$ at a rate of $1^{\circ}$ per minute and the powder X-ray diffraction patterns were indexed.

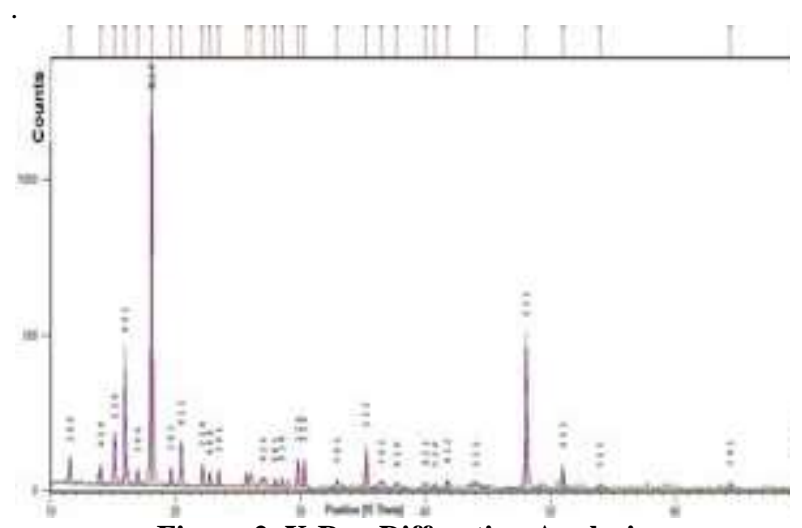

\subsection{FT-IR analysis}

Fourier Tranform Infrared (FT-IR) spectrum was recorded with a Perkin-Elmer RXI spectrometer using $\mathrm{KBr}$ pellet technique. The wave number was varied between 400 and $4000 \mathrm{~cm}^{-1}$ in order to confirm the presence of functional groups and the coordination of ligand-to-metal ions. The recorded FT-IR spectrum of the TTMZS compound is shown in figure 3. In the high frequency region sharp intense peaks observed at 3313 and $3192 \mathrm{~cm}^{-1}$ are attributed to asymmetric and symmetric stretching vibrational modes of $\mathrm{NH}_{2}$ group present in the Thiourea molecule. The $\mathrm{NH}_{2}$ bending of Thiourea is observed to form a broad envelope between 3300 and $1600 \mathrm{~cm}^{-1}$ due to its Hydrogen bonding interaction with the neighbouring anion complex. The $\mathrm{C}=\mathrm{S}$ stretching in Thiourea molecule coordinated with Magnesium and Zinc Sulphate is observed at 1508 (asymmetric) and 712 (symmetric) (Table 2).
Besides, this interaction is also evident to be a shift in the N$\mathrm{C}-\mathrm{N}$ stretch of Thiourea to higher value in TTMZS crystals compared to pure Thiourea.

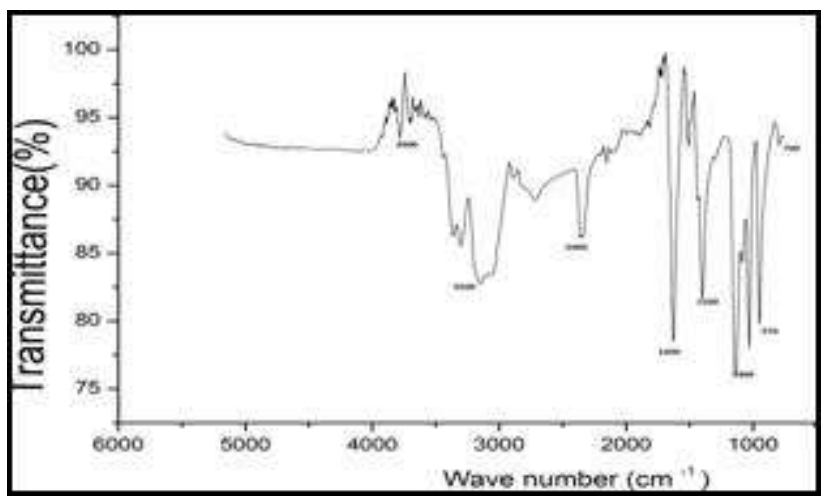

Figure 3. FT-IR Analysis

In pure Thiourea, $\mathrm{C}=\mathrm{S}$ is bonded to $\mathrm{NH}_{2}$, whereas in TTMZS crystals it is bonded to metal ions and therefore the $\mathrm{C}=\mathrm{S}$ stretching vibration is also shifted to lower values from 730 to $713 \mathrm{~cm}^{-1}$. This shifting of $\mathrm{C}=\mathrm{S}$ stretching frequency confirms the coordination of metal-sulphur bond. The intense band at $618 \mathrm{~cm}^{-1}$ is due to $\mathrm{NH}_{2}$ bending vibration. The peak at $1627 \mathrm{~cm}^{-1}$ with very strong intensity can be attributed to the $\mathrm{NH}_{2}$ asymmetric bending vibrations. The strong band centered at $1122 \mathrm{~cm}^{-1}$ corresponds to $\mathrm{NH}_{2}$ rocking vibrations. The $\mathrm{N}-\mathrm{C}$ $\mathrm{N}$ symmetric stretching vibration of pure Thiourea occurs at $1470 \mathrm{~cm}^{-1}$. The strong peak at $1399 \mathrm{~cm}^{-1}$ can be attributed to $\mathrm{C}=\mathrm{S}$ asymmetric stretching vibration of TTMZS complex. From the FT-IR spectral analysis, the presence of functional groups and the coordination ligand of TTMZS were confirmed and the assignment of functional groups is compared with Tris Thiourea Magnesium Sulphate (MTS) [12] is given in table below.

Table 2. Indexed powder XRD pattern of TTMZS.

\section{UV-Vis Studies}

\begin{tabular}{|l|l|l|}
\hline $\begin{array}{c}\text { TMS } \\
\text { Wave } \\
\text { Number } \\
\left(\mathbf{C m}^{-1}\right)\end{array}$ & $\begin{array}{c}\text { TTMZS } \\
\text { Wave } \\
\text { Number } \\
\left(\mathbf{C m}^{-1}\right)\end{array}$ & \multicolumn{1}{|c|}{ Assignments } \\
\hline 3368 & 3313 & Symmetric stretching $\left(\mathrm{NH}_{2}\right)$ \\
\hline 1611 & 1627 & $\mathrm{NH}_{2}$ bending \\
\hline 1472 & 1508 & $\mathrm{C}=\mathrm{S}$ Stretching (Asymmetric) \\
\hline 713 & 712 & $\mathrm{C}=\mathrm{S}$ Stretching(Symmetric) \\
\hline 619.04 & 618 & $\mathrm{~N}-\mathrm{C}-\mathrm{N}$ Asymmetric stretching \\
\hline 955 & 900 & N-C-N symmetric Stretching \\
\hline
\end{tabular}

The UV-Vis transmittance spectrum of a TTMZS crystal with $2 \mathrm{~mm}$ thickness was recorded using Perkin Elmer-Lambda 35 $\mathrm{UV}-\mathrm{V}$ is spectrophotometer in the range of $190-1100 \mathrm{~nm}$. The figure below shows the transmittance spectrum for the entire visible region. The UV transparency lower cutoff wavelength occurs at $280 \mathrm{~nm}$. The absence of absorption of light in the visible region (300-800 nm) makes TTMZS crystals very suitable for optoelectronic applications. 


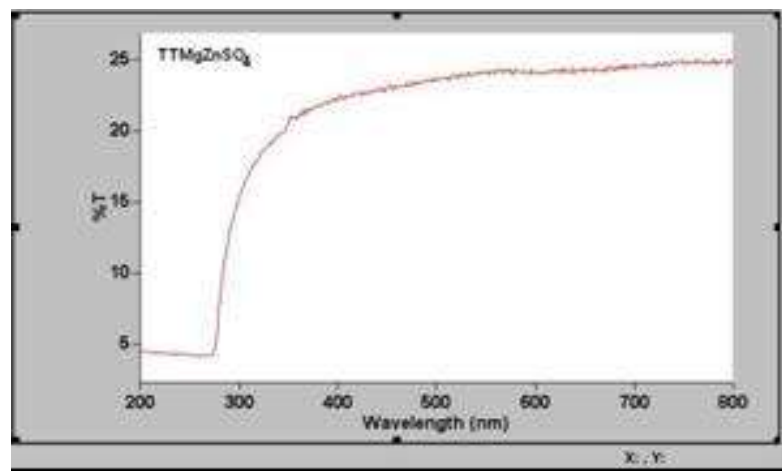

Figure 4. UV-Vis transmittance spectrum of TTMZS

\subsection{Thermal Analysis}

Thermal analysis was carried out using SDT Q600V 8.3 build 101 simultaneous DTA/TGA analyzer in a nitrogen atmosphere. The Thermo Gravimetric Analysis (TGA) and Differential Thermal Analysis (DTA) were carried out for a sample of weight $2.5510 \mathrm{mg}$ in the temperature range 20$1200^{\circ} \mathrm{C}$ at a heating rate of $20^{\circ} \mathrm{C} / \mathrm{min}$ in nitrogen atmosphere (figures 4 and 5). From TGA it is observed that the crystal TTMZS has good thermal stability up to $248.68^{\circ} \mathrm{C}$ as there is no weight loss below that temperature.

The TGA curve also shows that there is a weight loss of about $55.3 \%$ in the temperature range $300^{\circ} \mathrm{C}-362.88^{\circ} \mathrm{C}$ due to the liberation of volatile substance in the compound. The DTA curve shows the exothermic peak at $248.75^{\circ} \mathrm{C}$ - the melting point of the substance - and it undergoes an irreversible endothermic transition thereafter.

The second endothermic peak at $306.78^{\circ} \mathrm{C}$ indicates major decomposition of the material. The sharpness of the endothermic peak shows a good degree of crystallinity of the grown crystal TTMZS.

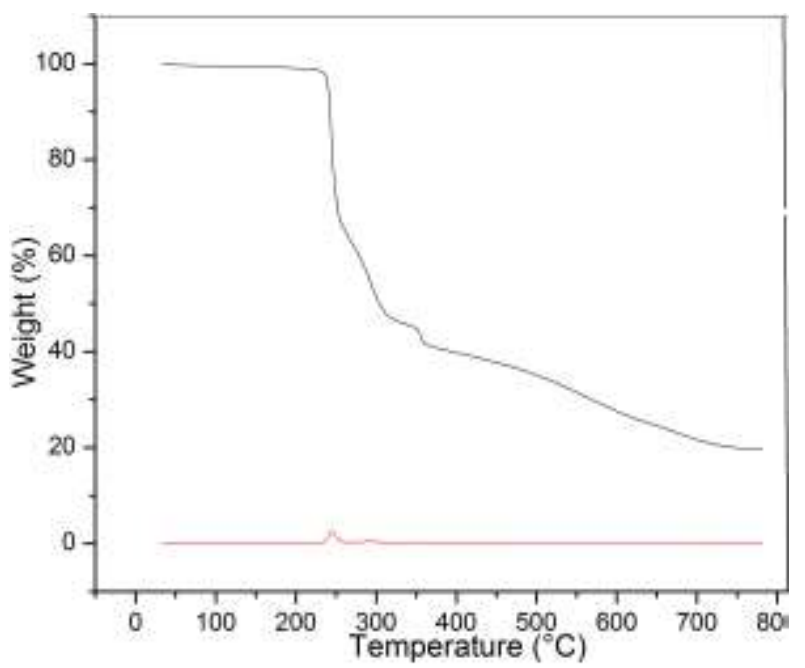

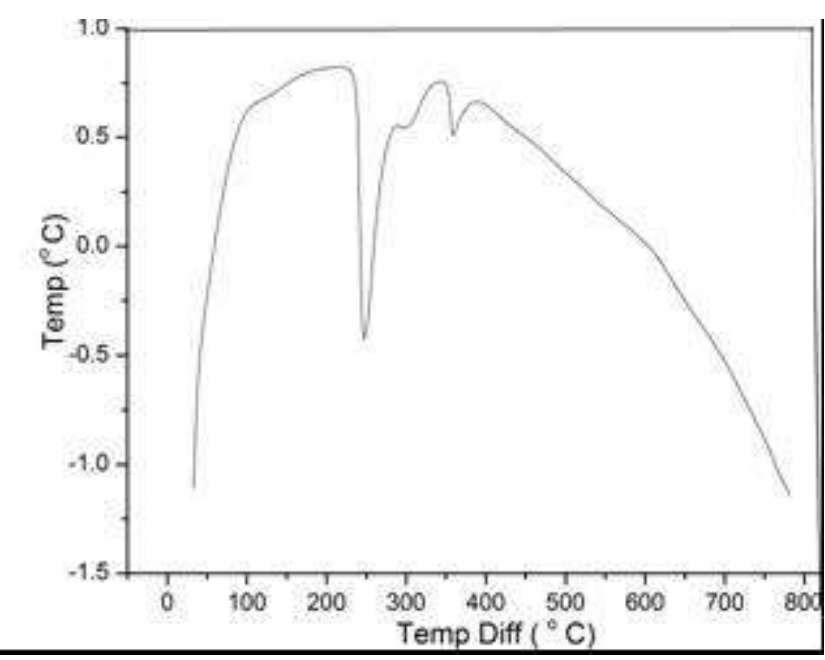

Figure 5. TGA Analysis of TTMZS Crystal.

\subsection{NLO Analysis}

The Second Harmonic Generation (SHG) conversion efficiency of TTMZS was measured by powder Kurtz and Perry Powder Technique [11]. The crystal was ground into a fine powder and densely packed between two transparent glass slides. A Q-switched Nd:YAG laser emitting a fundamental wavelength of $1064 \mathrm{~nm}$ (pulse width $8 \mathrm{~ns}$ ) was allowed to strike the sample cell. The SHG output $532 \mathrm{~nm}$ (green light) was finally detected by the photomultiplier tube. Powdered Potassium Dihydrogen Phosphate (KDP) was used in the same experiment as a reference material.

\subsection{EDAX Analysis}

EDAX (Elemental Dispersive X-ray Analysis) is a widely used technique to analyze the chemical components in a material under a scanning electron microscope. This method detects the X-rays produced as the result of the electron beam interactions with the sample. Mapping X-ray data is processed to obtain the percentage of each measured element present in the individual particles. In this communication we have found the accurate proportion of Magnesium and Zinc molecules in the TTMZS complex.

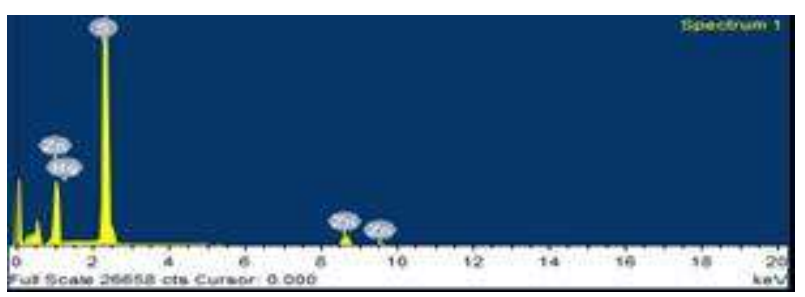

Figure 7. EDAX Analysis of TTMZS Crystal 


\section{CONCLUSION}

Pure TTMZS single crystals of good optical quality have been grown by the Solution Growth method at room temperature. The lattice parameters have been determined by Single Crystal X-ray Diffraction technique. The FT-IR spectrum reveals the various functional groups present in the grown crystal. The optical absorption spectrum reveals that the absorbance is less than one unit between 300 and $1200 \mathrm{~nm}$. TGA and DTA studies reveal that the TTMZS crystals have good thermal stabilities. The studies on the NLO property confirms the second harmonic conversion efficiency of the crystal to be better than that of KDP.

\section{REFERENCES}

[1] Monaco, S.B., Devis L.E., Velsk, S.P., Wang, F.T. Eimeral, D., J. Cryst. Growth 85 (1987) 252.

[2] Marcy,H.O., Rosker, M.J. Warren, L.F., Cunningham, P.H. Thomas,, C.A., Deloach, L.A., Velsko, S.P., Ebbers, C.A., Liao, J.H., Kanatzidis, M.G., Opt.Lett. 20 (1995) 252

[3] Jiang, M.H., Fang, Q., Adv. Mater. 119 (1999) 1147.

[4] Coe, B.J., Mccleverty,J.A., Meyer, T.J. (Eds.), Comprehensive Coordination Chemistry II, vol. 9, Elsevier Pergamon, Oxford, UK, 2004, pp. 621-687.

[5] Marcy, H.O., Warren, L.F., Webb, M.S., Ebbers, C.A. Velsko, S.P., Kennedy, G.C., Catella, G.C., Appl. Opt. 31 (1992) 5051.
[6] Venkataraman, V., Subramaniam, C.K., Bhat, H.L J. Appl. Phys. 77 (1995)6049.

[7] Ramajothi, J. Dhanuskodi, S. Nagarajan, K. Cryst. Res. Technol. 39 (2004)414.

[8] Ramabadran, U.B., Zelmon, D.E., Kennedy, G.C., Appl. Phys. Lett. 60 (1992)2589.

[9] Ramabadron, U.B., Mcpherson, A.L. Zelmon, D.E. J. Appl. Phys. 76 (1994) 1150.

[10] Venkataramanan, V., Dhanaraj, G., Wadhawan, V.K. Sherwood, J.N., Bhat, H.L. J. Cryst. Growth 154 (1995) 92.

[11] Ushasree, P.M., Jayavel, R., Subramanian Ramaswamy, P., J. Cryst.Growt 197 (1999) 216.

[12] Ghatak, A., Thyagarajan, K. Optical Electronics, Cambridge University Press, ,1994 